Article

\title{
A High Gain DC-DC Converter with Grey Wolf Optimizer Based MPPT Algorithm for PV Fed BLDC Motor Drive
}

\author{
A. Darcy Gnana Jegha ${ }^{1}$, M. S. P. Subathra ${ }^{1, *}$, Nallapaneni Manoj Kumar ${ }^{2, *} \mathbb{C}^{\text {, }}$ \\ Umashankar Subramaniam ${ }^{3}$ and Sanjeevikumar Padmanaban $4, *$ D \\ 1 Department of Electrical and Electronics Engineering, Karunya Institute of Technology and Sciences, \\ Coimbatore 641114, India; darcyjegha@gmail.com \\ 2 School of Energy and Environment, City University of Hong Kong, Kowloon, Hong Kong \\ 3 Renewable Energy Lab, College of Engineering, Prince Sultan University, Riyadh 12435, Saudi Arabia; \\ usubramaniam@psu.edu.sa \\ 4 Department of Energy Technology, Aalborg University, 6700 Esbjerg, Denmark \\ * Correspondence: subathra@karunya.edu (M.S.P.S.); nallapanenichow@gmail.com (N.M.K.); \\ san@et.aau.dk (S.P.)
}

Received: 22 February 2020; Accepted: 15 April 2020; Published: 17 April 2020

\begin{abstract}
Photovoltaic (PV) water pumping systems are becoming popular these days. In PV water pumping, the role of the converter is most important, especially in the renewable energy-based PV systems case. This study focuses on one such application. In this proposed work, direct current (DC) based intermediate DC-DC power converter, i.e., a modified LUO (M-LUO) converter is used to extricate the availability of power in the high range from the PV array. The M-LUO converter is controlled efficiently by utilizing the Grey Wolf Optimizer (GWO)-based maximum power point tracking algorithm, which aids the smooth starting of a brushless DC (BLDC) motor. The voltage source inverter's (VSI) fundamental switching frequency is achieved in the BLDC motor by electronic commutation. Hence, the occurrence of VSI losses due to a high switching frequency is eliminated. The GWO optimized algorithm is compared with the perturb and observe (P\&O) and fuzzy logic based maximum power point tracking (MPPT) algorithms. However, by sensing the position of the rotor and comparing the reference speed with the actual speed, the speed of the BLDC motor is controlled by the proportional-integral (PI) controller. The recent advancement in motor drives based on distributed sources generates more demand for highly efficient permanent magnet (PM) motor drives, and this was the beginning of interest in BLDC motors. Thus, in this paper, the design of a high-gain boost converter optimized by a GWO algorithm is proposed to drive the BLDC-based pumping motor. The proposed work is simulated in MATLAB-SIMULINK, and the experimental results are verified using the dsPIC30F2010 controller.
\end{abstract}

Keywords: PV water pumping; high gain DC-DC converter; modified LUO converter; hybrid MPPT algorithm; grey wolf optimizer

\section{Introduction}

The brushless DC (BLDC) motor is commonly used for low and medium power applications because of its high torque/inertia ratio, high efficiency, low electromagnetic interference and lower maintenance. The BLDC motor is also widely used in aerospace, medical, servo appliances, electric vehicles and robotic applications [1,2]. These motors need electronic commutators, which require information about the rotor position to achieve commutation using a voltage source inverter. The speed-torque characteristics of BLDC motors are very significant, and there is no need for 
the placement of brushes, which in turn reduces the copper and eddy current losses. Due to its permanent magnet excitation, no excitation losses occur, and this enhances the efficiency of the BLDC motor to a sufficiently high value. Photovoltaic (PV) systems can be used to supply power to the BLDC motor for the pumping application [3]. In the conventional method, the motor is driven utilizing a single-phase controlled bridge rectifier. At the output side of the rectifier, a smoothening direct current-link (DC-link) capacitor is used [4]. Owing to the unbalance in the charging and discharging of the DC link capacitor, a higher peak current compared to the fundamental input current occurs, distorting the input alternating current $(\mathrm{AC})$ current. Due to this very high current, the total harmonic distortion (THD) also increases in the range of $65 \%-70 \%$. Thus, power quality problems occur, in addition to the notching effect and crest factor $[5,6]$.

The BLDC motor drives typically work in a two-phase conduction mode, and during the commutation period it switches over to the three-phase conduction mode. This process is known as overlapped commutation mode. Due to this, there will be an increase in the overlapping current, which in turn produces commutation torque ripples in the BLDC motor drive [7]. Direct current-direct current (DC-DC) converters are classified as non-isolated and isolated converters. The isolated DC-DC converters are used for high voltage conversion where the conduction loss may occur owing to an energy transfer from secondary to the primary winding. However, the non-isolated DC-DC converters are quite reasonable as they are only used for low voltage conversion [8]. The non-isolated DC to DC converters has many salient features when used with the PV system [9]. Overall, the non-isolated DC to DC converters has an excellent performance in the PV system [10]. When the converters operate in a Continuous Conduction Mode (CCM), they offer reduced stress on the switches of the converters, but still, the need for three sensors, a power supply and dc-link voltages increase the cost of converters. When the converter operates in a discontinuous mode, it offers more stress on the converter switches, which requires a mono voltage sensor for controlling the dc-link voltage [11].

The selection of DC-DC converters plays a vital role in deciding the optimum performance of BLDC drives. Research in the field of renewable energy sources shows that general integration has been done with the DC-DC converter topology. From various literature reviews, it is shown that buck converters have been used in speed drive regulation and the reduction of torque ripple by pulse width modulation (PWM) chopping techniques [12]. Richter, 2017 [13] and Singh \& Bist 2015, [14] discussed several configurations related to converter-fed BLDC drives. In most cases, the boost converter configuration has been given much importance despite its disadvantage of switching losses that occur in VSI due to the high-frequency PWM signal. For overcome this, low-frequency switching signal based electronic commutators is put in use to control the speed of BLDC drives through voltage source inverter's (VSI) [15]. Variable voltages of the Cuk converter VSI have been used for controlling the speed and VSI functions at the fundamental frequency, thereby reducing switching losses. The main drawback of this system is that, in CCM mode, three sensors are required to limit the voltage and control the speed of the BLDC drive. It also provides an inverting output, which increases the system complexity and slows down the system response, which would, therefore, not match with the system's requirement [16]. Kumar \& Singh 2014, [17] used the buck-boost converter for water pumping application and for soft-starting the BLDC by proper control. Buck-boost converters have a discontinuous output current which produces ripples and switching losses in VSI. Kumar \& Singh 2016, [18] used a Zeta converter, where PWM pulses have controlled the voltage source inverter's switching sequences. Due to this, a high switching loss occurs on the VSI. Berkovich et al., 2015 [19] used LUO converter with the switched inductor to boost the voltage, and by adding a magnetically coupled inductor, diode and capacitor, the voltage gain is multiplied. A PV system-fed BLDC motor with a Cuk converter-based maximum power point tracking (MPPT) algorithm eliminates the ripple filter, and speed control is achieved through a variable DC link voltage [20]. Depending on the application, different DC-DC converters can be used in renewable energy sources to improve the efficiency of the system [21]. An MPPT based on the Fuzzy and Artificial Bee Colony (ABC) algorithm with a zeta converter was designed, where the sensors and PI controllers in the system often got 
affected due to the environmental conditions [22]. The closed-loop speed control of the BLDC motor is implemented with the dSPACEDS1103 controller for controlling the speed at a reference value for low to high speeds [22]. Additionally, by self-tuning the fuzzy proportional-integral-derivative (PID) controller, the rotor speed is forced to track the reference speed at all times [23]. The closed-loop speed control of the BLDC motor is obtained from the optimized fuzzy algorithm [24]. A DC-DC boost converter is utilized between the solar PV array and permanent magnet motors, by which the friction between the brushes increases and the torque is lowered [25].

A simple and efficient solar water pumping system using a modified LUO converter has been proposed in this paper. A BLDC motor is attracting much interest, because of its higher efficiency, better performance and simple control when applied in many applications. The induction motors have a nearly $10 \%$ lower efficiency than PM motor drives for energy saving applications. The increase in energy demand spurs higher demands for variable speed PM motor drives. A modified LUO converter with an efficient grey wolf optimizer (GWO) MPPT algorithm extracts the maximum power from the PV panel. This converter also provides a low starting current for the BLDC motor, which overcomes the torque ripple problems in the BLDC motor.

The manuscript is structured as follows, in six different sections: in Section 2, the systematic working of the proposed system is presented. In Section 3, the design of the proposed system considering each electrical component is discussed, and detailed mathematical modelling is given. Section 4 presents a brief theory on the perturb and observe (P\&O), fuzzy and GWO MPPT algorithms, as well as a detailed flow chart of the GWO algorithm. The simulation and experimental results of the proposed system are presented and discussed in Section 5. Finally, the main conclusions are drawn from the study and views on future works are given in Section 6.

\section{Systematic Working of the Proposed System}

The configuration of the developed solar-fed BLDC motor using a modified LUO converter is shown in Figure 1. The proposed modified LUO converter operates with a single switch in a continuous conduction mode. This increases the efficiency and suppresses the ripple in the output voltage. The single switch operation reduces the switching stress of the converter. The continuous conduction mode reduces the heat produced in the power semiconductor devices.

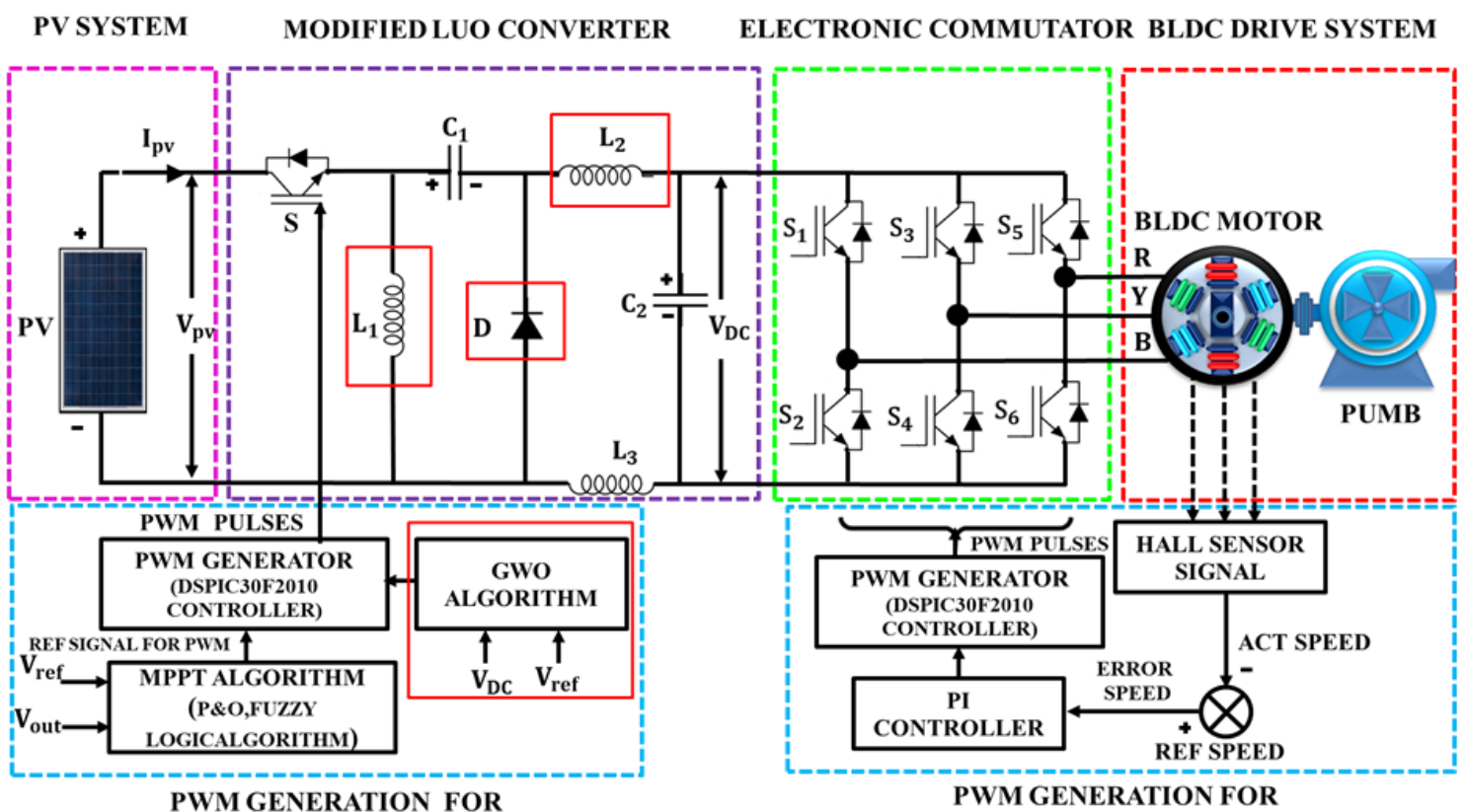
AC-DC CONVERTER

ELECTRONIC COMMUTATOR

Figure 1. Proposed solar-based system for motor pumping. 
The proposed GWO-optimized algorithm reduces the maximum power tracking time and makes the output voltage nearly constant. This constant voltage is fed to the three-phase electronic commutator, which converts the DC into three-phase AC voltage. For find the rotor position, three hall sensors are set up in the rotor displaced by $60^{\circ}$ mechanicals. The input current is continuous because of the modified LUO converter, and this makes the BLDC motor make a soft starting. The proportional-integral (PI)-based motor speed control achieves a constant speed of operation [26]. This makes the proposed work highly efficient in a way that could easily be carried out in a low-cost budget. The proposed system is developed using the dsPIC30F2010 microcontroller by Microchip Technology Inc., USA, and the experimental results are verified using the MATLAB Simulink tool by MathWorks, USA.

This system consists of a $1000 \mathrm{~W}$ solar panel, insulated-gate bipolar transistor (IGBT)-based modified LUO (M-LUO) converter with an active snubber circuit and IGBT-based VSI with a 3 phase, 1 horsepower (HP) BLDC motor employed with a Hall Effect sensor. Additionally, a dsPIC30F2010 controller is used as a pulse generator, which is controlled by the GWO algorithm. The driver circuit drives the IGBT switch. The system functions when the input from the solar array voltage is given to the modified, LUO converter for maintaining constant voltage, with less ripple content delivered to the inverter system.

The output of the LUO converter is used as an input for the GWO algorithm. For tracking the maximum power, the proposed GWO algorithm is advantageous. This algorithm produces PWM pulses based on the variation of the PV panel voltage, thereby adjusting the duty cycle of the M-LUO converter. In the M-LUO converter, the elementary LUO converter is added with one extra inductor. This converter acts as a second-order low pass filter, and therefore it does not require another filter circuit. This converter with the GWO algorithm provides a constant voltage to all the three phases of the electronic commutator. Switching is done with the help of Hall Effect voltage sensors. The three-phase voltage source inverter converts the DC voltage into AC voltage to provide power to the BLDC motor. The inverter system works at a fundamental frequency to eliminate the high-frequency noise in the inverter output, and high efficiency is thus attained.

\section{Proposed System Design}

The modelling steps are explained appropriately to make a compelling design of the proposed system, capable of operating in certain determined conditions. A BLDC motor with $1 \mathrm{HP}$ power and a solar panel of the maximum power capacity of $800 \mathrm{~W}$ under standard test conditions (STC) are deliberated. Figure 2 shows a schematic representation of the solar cell. In Figure 2a,b, the simplified diagram and the equivalent diagram of the solar cell are represented, respectively. The current $I_{p h}$ represents the current generated due to photons. $I_{p h}$ mainly depends on the incident radiant energy emitted by the sun and its temperature. One single solar cell is designed by using one photon source current, one diode and one set of series and shunt resistors grouped in a series and parallel fashion, forming a photovoltaic cell.
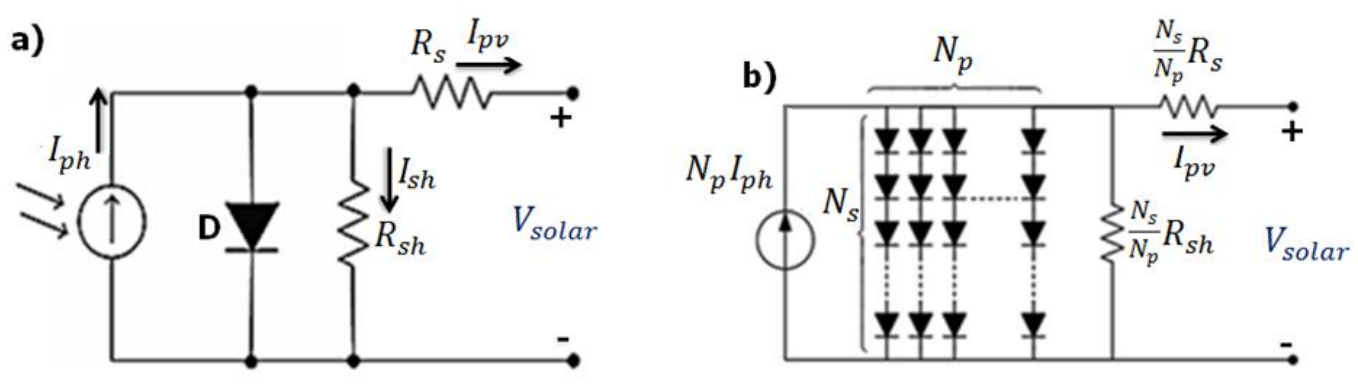

Figure 2. Schematic representation of the solar cell. (a) Simplified diagram of the solar cell; (b) Equivalent diagram of the solar cell. 


\subsection{Modelling of the Solar Cell}

The output current from the solar cell is:

$$
I=N_{P} \times I_{p h}-N_{P} \times I_{0} \times\left[e^{\left(\frac{\frac{V}{N_{S}}+I \times \frac{R_{s}}{N_{P}}}{n^{*} V_{t}}\right)-1}\right]-I_{s h}
$$

The diode thermal voltage is given as:

$$
V_{t}=\frac{k \times T}{q}
$$

The shunt current is given as:

$$
I_{s h}=\frac{V \times \frac{N_{P}}{N_{s}}+I \times R_{s}}{R_{s h}}
$$

where $N_{P}$ is the number of modules connected in parallel; $R_{S}$ is the series resistance; $R_{s h}$ is the shunt resistance; and the diode thermal voltage is $V_{t}$.

With the available physical and mathematical model, various parameters of the solar cell can be estimated. These include the estimated power, output voltage and maximum short circuit current. In the proposed study, a solar panel with the specifications shown in Table 1 is used.

Table 1. Specification of the solar panel.

\begin{tabular}{cc}
\hline Parameter & Value with Units \\
\hline Peak power $\left(\mathrm{P}_{\mathrm{mp}}\right)$ & $100 \mathrm{~W}$ \\
\hline Open Circuit Voltage $\left(\mathrm{V}_{\mathrm{oc}}\right)$ & $22.68 \mathrm{~V}$ \\
\hline Short circuit current $\left(\mathrm{I}_{\mathrm{sc}}\right)$ & $5.86 \mathrm{~A}$ \\
\hline Peak power voltage $\left(\mathrm{V}_{\mathrm{mp}}\right)$ & $18.75 \mathrm{~V}$ \\
\hline Peak power current $\left(\mathrm{I}_{\mathrm{mp}}\right)$ & $5.42 \mathrm{~A}$ \\
\hline Number of series-connected cells $\left(\mathrm{N}_{\mathrm{s}}\right)$ & 36 \\
\hline
\end{tabular}

\subsection{Design of the Proposed System}

The design of the M-LUO converter-fed BLDC for the water pumping application is discussed in this section. The components, such as the input inductor, capacitors $L_{1}$ and $C_{1}$ respectively, output inductors $L_{2}, L_{3}$ and output dc-link capacitor $C_{2}$ work in a continuous conduction mode with low stress on the devices and its elements. Depending on the duty cycle, the mode of operation can be changed.

$$
\text { Duty cycle }=V_{\text {out }} /\left(V_{\text {out }}+V_{\text {solar }}\right)=300 /(300+56)=0.84
$$

where $V_{\text {out }}$ is the average value of the output voltage of the LUO converter, which is equal to the BLDC motor's input voltage.

The estimated output current can be written as:

$$
I_{0}=P_{\text {out }} / V_{\text {out }}
$$

The BLDC motor rating is taken as $P_{\text {out }}=746 \mathrm{~W}$ :

$$
I_{0}=746 / 300=2.48 \mathrm{~A}
$$


Then, the estimated maximum permitted ripple values of $L_{1}$ and $C_{1}$ are:

$$
\begin{aligned}
\Delta I_{L}= & I_{0} \times \frac{V_{0}}{V_{\text {in }(\min )}} \\
= & 2.48(300 / 56)+30 \% \text { ripples } \\
= & 13.28+3.98 \\
= & 17.26 \mathrm{~A} \\
& \Delta I_{L}=\Delta I_{l 1}=\Delta I_{l 2}
\end{aligned}
$$

The inductor $\mathrm{L}_{1}$ in the modified LUO converter is calculated by the following equation:

$$
\begin{aligned}
L_{1} & =\mathrm{D} V_{\text {solar (in) }} / f_{\text {sw }} \Delta I_{l 1} \\
& =0.84 \times 56 / 10 \times 10^{3} \times 17.26 \\
L_{1} & =0.273 \mathrm{mH}
\end{aligned}
$$

The inductances $\mathrm{L}_{2} \& \mathrm{~L}_{3}$ in the modified LUO converter are calculated by the following equation:

$$
\begin{aligned}
L_{2} & =(1-\mathrm{D}) V_{\text {solar (in) }} / f_{s w} \Delta I_{l 2} \\
& =(1-0.84) \times 56 / 10 \times 10^{3} \times 17.26 \\
L_{2} & =0.052 \mathrm{mH}=L_{3}
\end{aligned}
$$

The change in the capacitor voltage across $C_{1}$ is given by:

$$
\begin{aligned}
\Delta V_{c S} & =I_{0} \times D / C_{s} f_{s w} \\
& =2.48 \times 17.26 / 10 \times 10^{-6} \times 10 \times 10^{3} \\
\Delta V_{c S} & =428.04 \mathrm{~V}
\end{aligned}
$$

The following equation calculates the capacitor $C_{1}$ in the modified LUO converter:

$$
\begin{aligned}
C_{1} & =I_{0} \times D / \Delta V_{c s} f_{s w} \\
& =2.48 \times 0.84 / 428.04 \times 10 \times 10^{3} \\
C_{1} & =486 \mathrm{nF}
\end{aligned}
$$

\subsection{Modelling of DC-Link Capacitor}

For the estimate, the VSI DC-link capacitor, the harmonic content present in the AC supply is reflected on the DC side as a prior harmonic in the three-phase supply system. The minimum and the maximum speeds for the BLDC motor can be calculated through the fundamental frequencies of the VSI. These two frequencies $\omega_{\max }$ and $\omega_{\min }$ are further used to calculate the dc link capacitance value which would satisfy the operation of the solar panel when working below the reduced level of irradiance. The highest capacitor value is chosen for designing a DC-link capacitor.

The fundamental output frequency of VSI corresponding to the maximum and minimum pumping speed requirement is:

$$
\begin{aligned}
\omega_{\max } & =2 \pi f_{\max }=\frac{2 \pi N_{\max } P}{120} \\
& =2 \pi \times 1500 \times \frac{6}{120}=471.20 \mathrm{rad} / \mathrm{s} \\
\omega_{\min } & =2 \pi f_{\min }=\frac{2 \pi N_{\min } P}{120} \\
& =2 \pi \times 1000 \times \frac{6}{120}=314.15 \mathrm{rad} / \mathrm{s}
\end{aligned}
$$

where $f_{\max }$ is the maximum fundamental frequency in $\mathrm{Hz}, f_{\min }$ is the minimum fundamental frequency in $\mathrm{Hz}$, and $\mathrm{P}$ is the number of poles of the BLDC motor. 
The corresponding capacitor can be calculated as:

$$
\begin{aligned}
C_{0 \text { max }} & =\frac{I_{0}}{6} \times \omega_{\max } \times \Delta V_{\text {out }} \\
& =\frac{2.5}{6} \times 471.2 \times 24 \times 0.05=736.8 \mu \mathrm{F} \\
C_{0 \text { min }} & =\frac{I_{0}}{6} \times \omega_{\max } \times \Delta V_{\text {out }} \\
& =\frac{2.5}{6} \times 314.15 \times 24 \times 0.05=1105.27 \mu \mathrm{F}
\end{aligned}
$$

where $\Delta V_{\text {out }}$ is the amount of the maximum permissible ripple voltage. Finally, $C_{0 \text { min }}$ is chosen to construct the DC link capacitor.

\subsection{Water Pump Design}

The water pump design relating to the power and speed for the proportionality constant has to be calculated:

$$
\begin{aligned}
\mathrm{K}= & \frac{\mathrm{P}}{\omega_{\max }^{3}}=\frac{60}{\left(2 \pi \times \frac{1500}{60}\right)^{3}} \\
& =1.52 \times 10^{-5}
\end{aligned}
$$

where $\mathrm{P}$ is the BLDC motor's rated power, and $\omega_{\max }$ is the motor's rated speed in rad/s.

\subsection{BLDC Motor Controlled by Electronic Commutation}

The BLDC motor is an electronically commutated device and requires data regarding the rotor position for the proper commutation of the stator current. The BLDC motor needs a quasi-rectangular shaped input current drawn into the machine. The back emf of each phase is trapezoidal and 120 electrical degrees-displaced. The BLDC motor is rotated in a sequence to energize the stator winding. Hall sensors sense the rotor position, and it is embedded into the stator. Whenever the magnetic poles of the rotor are nearer to the hall sensors, the sensors feed a low or high signal. The complete commutation sequence can be found by integrating the three-hall sensor output. Another important key factor of electronic commutation is high-frequency switching loss, which can be eliminated by providing the fundamental switching frequency of VSI. The switching sequences for the electronic commutation of the BLDC motor are the same as those employed in [18].

\section{Maximum Power Point Tracking (MPPT) Algorithm}

An MPPT algorithm is implemented to keep track of the changes caused by the environment and to extricate high power from the solar array. In a system with MPPT, voltage collapse is shunned when Maximum Power Point (MPP) is near to the operating point. The benefits of using the MPPT algorithm lie in its robustness and simplicity in implementation. In this paper, $\mathrm{P} \& \mathrm{O}$, fuzzy logic and GWO algorithms are compared to extricate high power from the PV system. There are different control algorithms available to monitor the maximum power point. Among these, $\mathrm{P} \& \mathrm{O}$ and Fuzzy logic are better choices of control algorithms. The main aim of this control algorithm is to adjust the variation of the voltage, current and power at the maximum power point obtained under the specific values of irradiance and temperature.

\section{1. $P \& O$ Algorithm}

In this algorithm based on the previous value of the power, the value of the reference voltage and current keeps on changing (i.e., increasing or decreasing) until it attains the maximum power point $[27,28]$. This perturbation causes changes in the power of the solar module. If the power increases due to the perturbation, it moves the operating point of the PV array to MPP and continues to disturb the PV voltage in the same direction. After reaching the maximum power, the next instant power reduces and consequently reverses the perturbation. The size of the perturbation kept is minimal in order to maintain the power variation. For set the reference perturbation voltage, the additional Proportional Integral controller was utilized to calibrate the duty cycle ratio of the MPPT-based converter. It was 
observed that there was some power loss due to this perturbation and that it sometimes also failed to track the power under rapidly varying atmospheric conditions. However, this algorithm is well known for its simplicity, showing better stability in the response under slow transient conditions and at a very high voltage oscillation.

\subsection{FUZZY Algorithm}

The Fuzzy algorithm overcomes the disadvantages of the P\&O algorithm. Fuzzy is one of the most optimal and attractive technical tools in all control fields as it deals with indefinite and uncertain information and makes decisions like humans. Thus, fuzzy control is applied to non-linear systems. The solar panel is a powerful, non-linear system. Various control algorithms have been worked out under the maximum power point tracking algorithm $[29,30]$. The fuzzy-based control algorithm is efficient because it can automatically adjust the output deviation to a constant value based on specific fuzzy rules. The control rules are framed, and the elements are determined based on the theory that in the transient state significant errors need coarse control which requires coarse input/output, while small errors need fine control which requires excellent input/output variables. Based on this, the elements of the rule table are obtained.

\subsection{GWO Algorithm}

The grey wolf optimization algorithm is being employed to achieve a better MPPT [9]. Mirjalili first proposed the Grey wolf algorithm in 2014. It is a mathematical model which follows the social behaviour of the grey wolf pack when hunting prey. The wolves in the pack are divided into different categories based on their fitness and strength. The different categories are alpha $(\alpha)$, beta $(\beta)$, delta $(\delta)$ and omega $(\omega)$. The fittest wolf in the pack is alpha $(\alpha)$, while the wolves with a fitness close to alpha are beta $(\beta)$ and delta $(\delta)$, and the rest of the wolves constitute omega $(\omega)$. The same structure is then used by the pack to hunt the prey by tracking, encircling and attacking. Here, the alpha $(\alpha)$, beta $(\beta)$ and delta $(\delta)$ wolves play the primary role.

The same phenomenon is considered in the GWO optimization model. The model divides the available solutions for a given problem into different categories as per their closeness to the desired output and also moves the solutions towards the desired values, just like the wolf pack tracking the prey, encircling the solution and finally achieving the desired solution. The solution which falls into alpha $(\alpha)$ is used by the mathematical model to reach the optimal solution. The equation used by the GWO to achieve this is given below:

$$
\begin{gathered}
\vec{X}(t+1)=\vec{X}_{p}(t)-\vec{A} \times \vec{D} \\
\vec{D}=\left|\vec{C} \times \vec{X}_{p}(t)-\vec{X}(t)\right|
\end{gathered}
$$

Here, it indicates the current iteration. $\vec{X}_{p}(t)$ represents the position of the desired output, and $\vec{X}(t+1)$ represents the position of the current solution. $\vec{A}, \vec{C}$ and $\vec{D}$ represent the vector coefficients, and these vectors are calculated using the below formula:

$$
\begin{gathered}
\vec{A}=2 \vec{a} r_{1}-\vec{a} \\
\vec{C}=2 \overrightarrow{r_{2}}
\end{gathered}
$$

where the values of the vector $a$ are linearly decreased from 2 to 0 as the iterations proceed, and $r_{1}, r_{2}$ are randomly chosen vectors in $[0,1]$.

In this paper, the GWO math model is used to achieve the maximum power point tracking with the help of a modified LUO converter whose switching pulse's duty cycle can be varied in an optimal 
way to achieve the maximum power from the PV array. The GWO performs the desired calculations to achieve MPP. The flow chart for the GWO-based MPPT is shown in Figure 3.

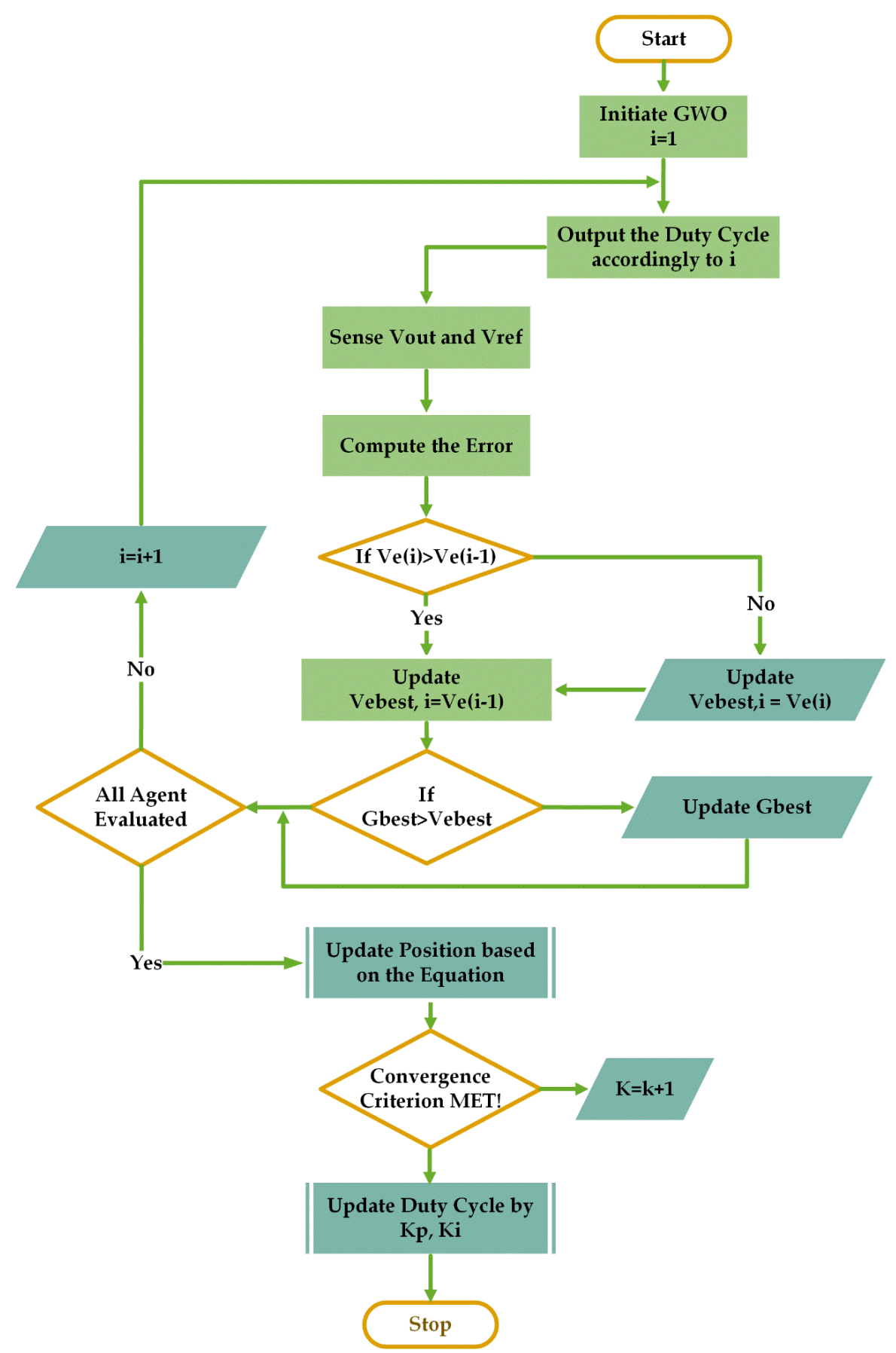

Figure 3. Flow chart of the Grey Wolf Optimizer (GWO)-based Maximum Power Point Tracking (MPPT) algorithm.

The duty cycle $(D)$ of the switching pulse of the modified Luo converter represents the Grey wolf. Therefore, we can rewrite Equation (17) as:

$$
D_{i}(k+1)=D_{i}(k)-A \times D
$$


The objective function of the proposed GWO algorithm is given by:

$$
V_{\text {act }}\left(D_{i}(k)\right)>V_{r e f}\left(D_{i}(k-1)\right)
$$

where $V$ indicates the output voltage, $\mathrm{d}$ is the duty cycle, ' $\mathrm{i}$ ' is the number of current Grey wolves and $\mathrm{k}$ is the number of iterations. For the MPPT tracking presented in this paper, the duty cycle of the DC-DC converter is referred to like the positions of the wolves in each state, and during iteration, the best value is considered as the $K_{\mathrm{P}}, \mathrm{K}_{\mathrm{i}}$ values of the PI controller.

\section{Simulation and Experimental Results of the Proposed System}

The proposed method is simulated using MATLAB. Here, in the DC-DC converters, IGBTs are utilized to reduce the switching power losses. The MPPT algorithm regulates the control signal produced by the PI controller, PWM pulses for the LUO converter and the input to the three-phase inverter. The proposed method is developed, modeled and simulated under starting and steady-state conditions.

\subsection{Simulation Results}

\subsubsection{Performance of the Converter}

The solar panel is consistently operated at the minimum and maximum power level utilizing the proposed GWO optimized algorithm. The tracking of the maximum power is purposely increased at the start in order to achieve the smooth start of the BLDC drive. The perturbation size is appropriately selected in order to avoid oscillation during the peak powerpoint. The DC link voltage across the capacitor is supplied to the VSI for the smooth start of the BLDC drive. The solar panel is operated under the conditions of dynamic variation due to changes in the irradiation level. Using the GWO algorithm, the proportional and integral gain is varied as it is mainly designed to obtain an excellent dynamic response under conditions of uncertainty and external disturbances. The GWO-based closed-loop control algorithm tracks the maximum power from the system. The output voltage (see in Figure 4a) and current (see in Figure 4b) waveforms of the solar PV panel are shown in Figure 4.
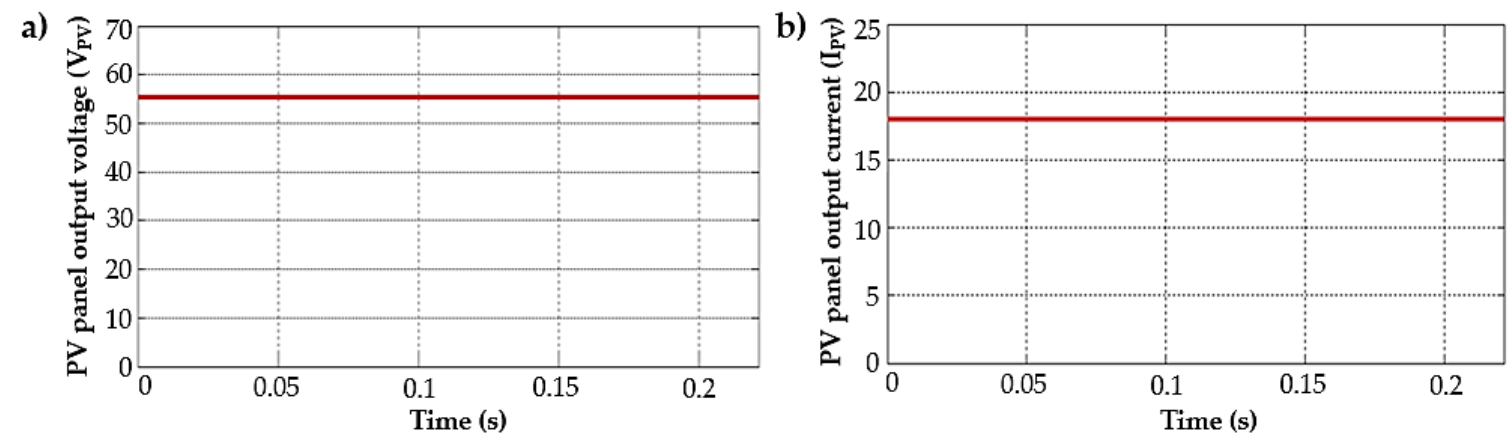

Figure 4. Solar Photovoltaic (PV) panel output. (a) Output voltage in Volts (V); (b) Output current in Amps (A).

From Figure 4, it is observed that the output voltage from the PV panel is approximately 55 Volts, and the output current generated by the PV panel is 17 Amps. Here, the PV panel is integrated with the MPPT technique. For prove the effectiveness of the proposed controller in MPPT tracking, a comparative study was done using various MPPT algorithms.

In Figure 5, the output waveform of the modified LUO converter using the GWO algorithm is shown. Initially, a peak is observed, and later at the time $>0 \mathrm{~s}$ the voltage value settles to a value of approximately 300 Volts. The output voltage produced by the proposed modified LUO converter is compared with the $\mathrm{P} \& \mathrm{O}$ and Fuzzy logic algorithms. 


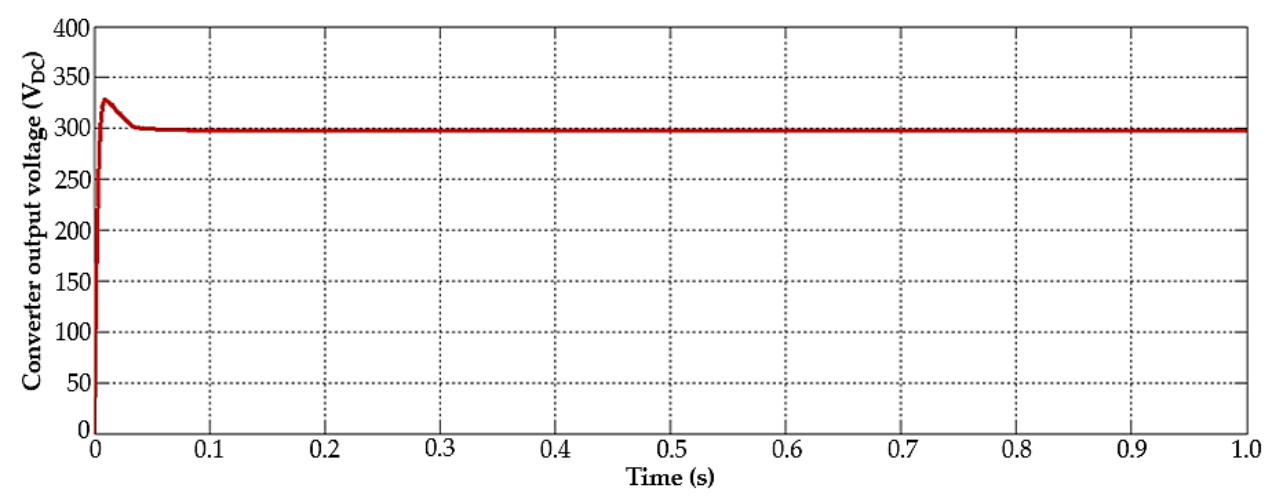

Figure 5. The output voltage waveform of the modified LUO converter using the GWO algorithm.

The input and output currents drawn by the proposed system are shown in Figure 6a,b, respectively. Here, the current ripples are maintained within the permissible limit. The three-phase output voltage waveform of the voltage source inverter is shown in Figure 7.
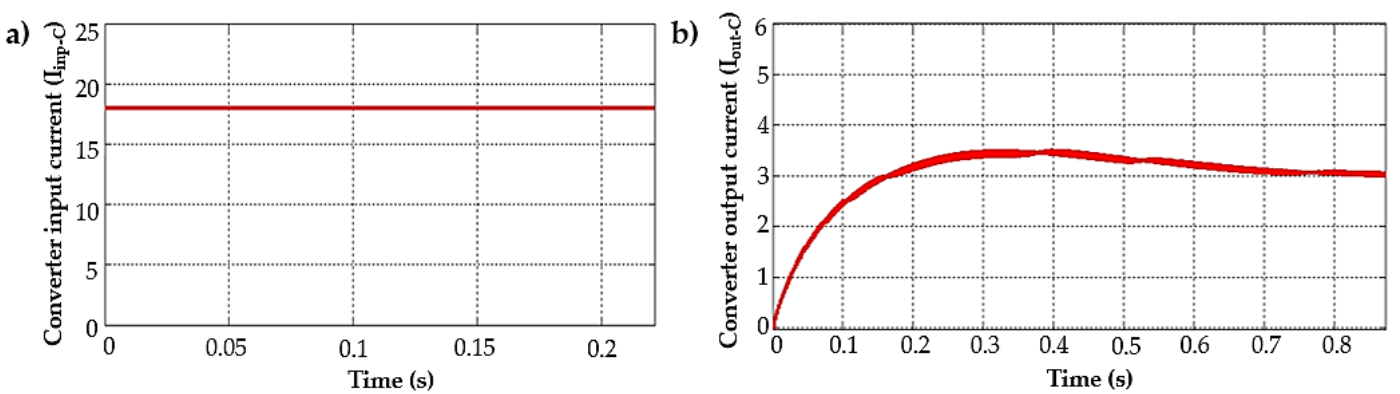

Figure 6. Current waveforms of the modified LUO converter using the GWO algorithm. (a) Converter input current; (b) Converter output current.

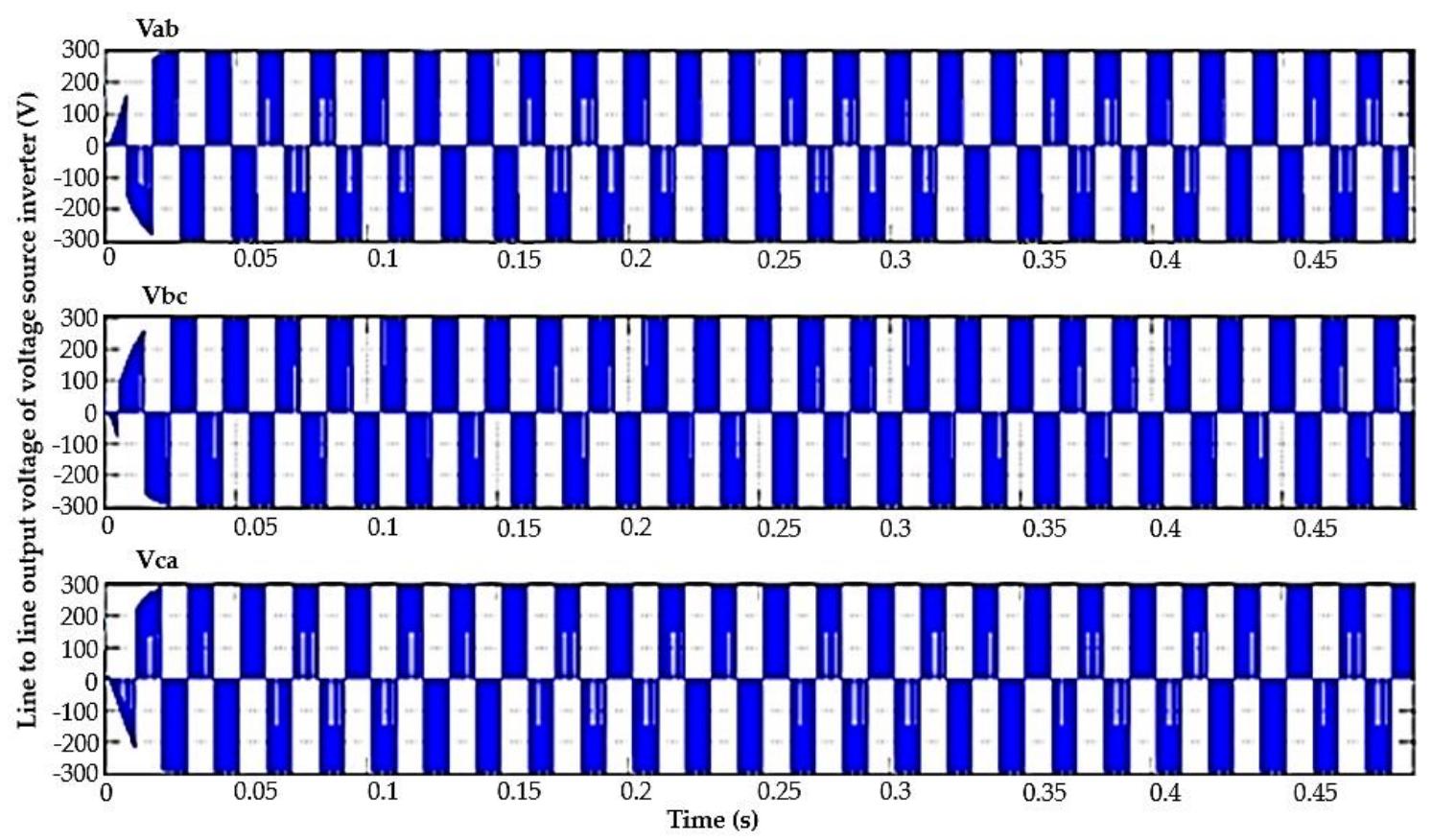

Figure 7. The output waveform of the voltage source inverter. 


\subsubsection{BLDC Motor Pump Performance}

Here, the starting and steady-state performances of the BLDC motor pump are exhibited. If there is any change in the level of irradiance, all the parameters in the BLDC motor pump vary according to the irradiance level. Usually, the BLDC runs above $1100 \mathrm{rpm}$. However, the required speed to pump water is below this speed at a low irradiance level of a minimum of $200 \mathrm{~W} / \mathrm{m}^{2}$. The proposed work is not intended to find the one among the best optimization algorithms, rather than to prove that the optimization technique can outperform the competitive fuzzy and elementary P\&O algorithms. The Luo converter and its modified versions are considered to measure the comparative performance of the BLDC motor. Figure 8 shows the output current waveforms of the BLDC motor for phases A, B and C, respectively. In Figure 9, the back emf of the BLDC motor is shown. The back emf cuts the magnetic flux and opposes the current flowing through the conductor. The starting value of the back emf is zero, and the values depend on the speed of rotation of the armature conductor.

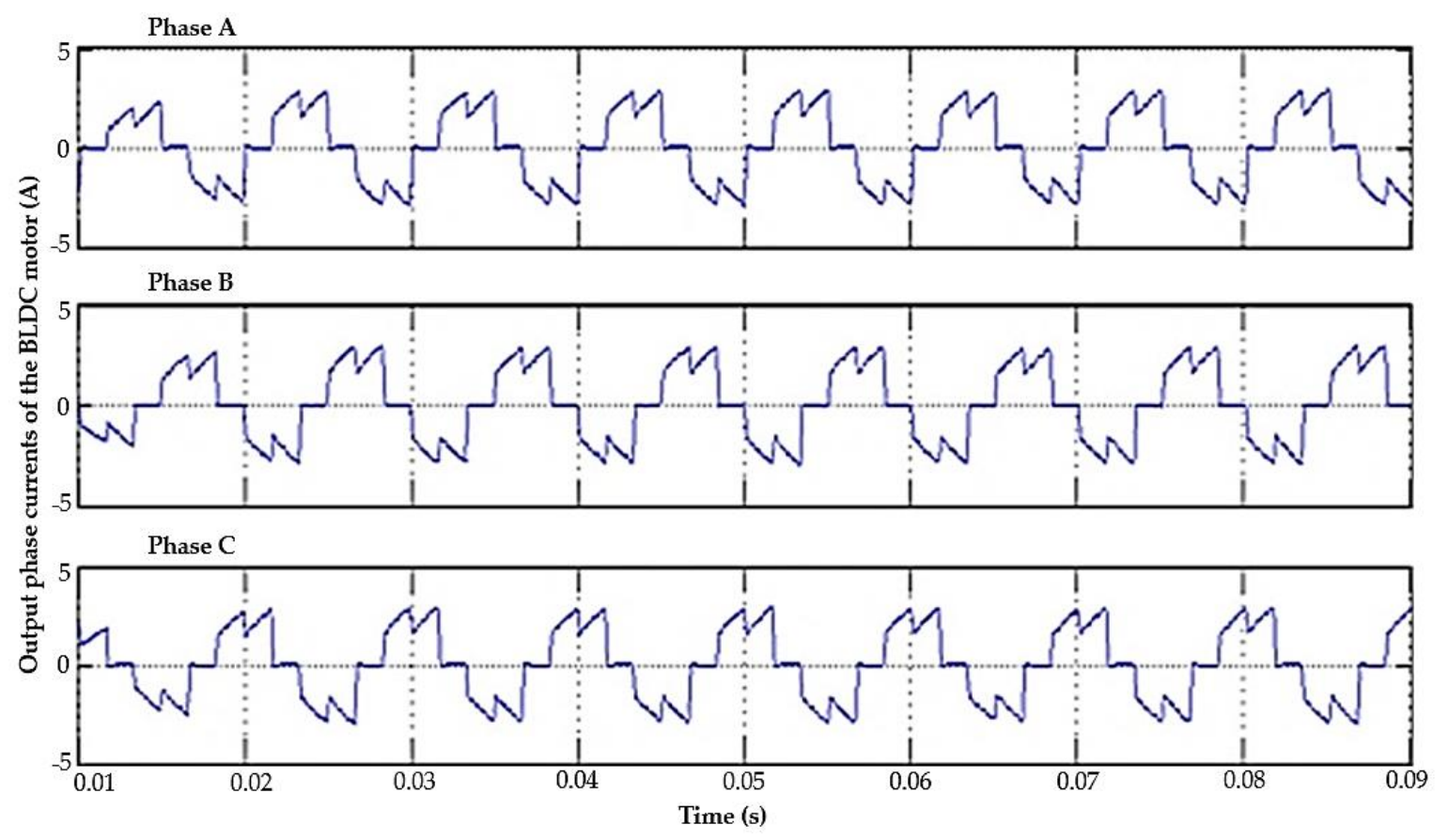

Figure 8. Output current waveform of the brushless DC (BLDC) motor.

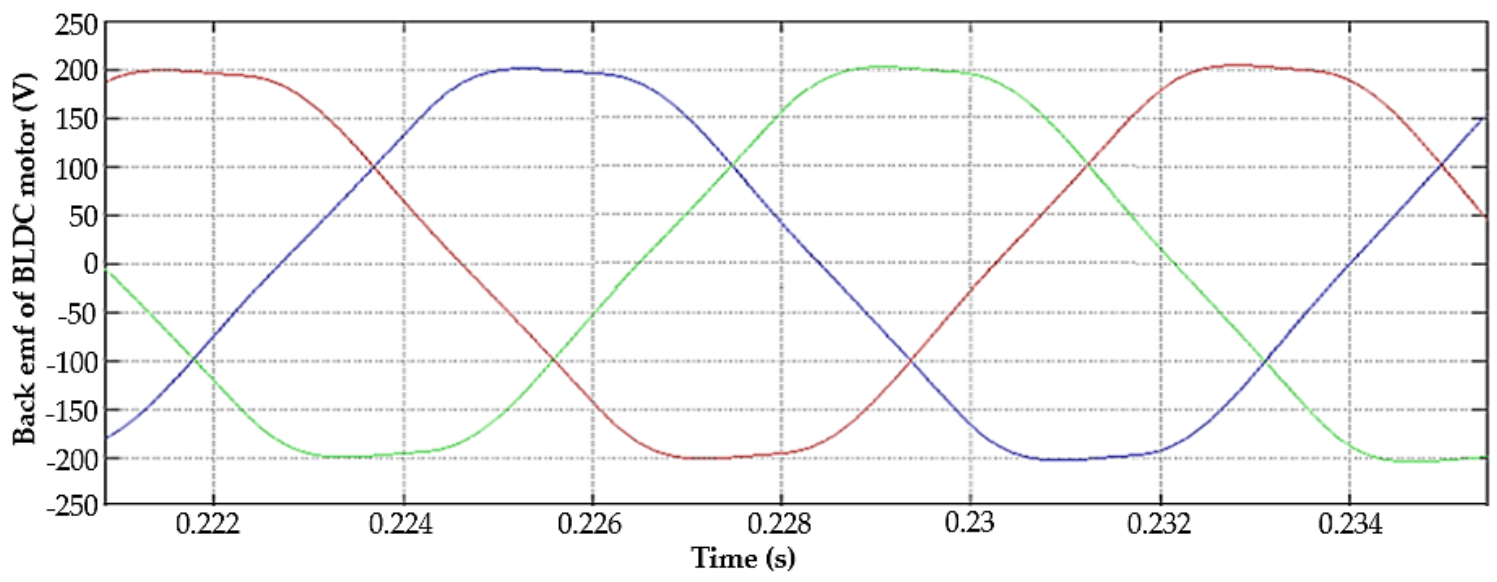

Figure 9. The back emf of the BLDC motor. 
Figure 10 shows the starting and steady-state behaviour of the BLDC motor. The speed and electromagnetic torque reach their steady-state value when the maximum power is tracked by the GWO algorithm.

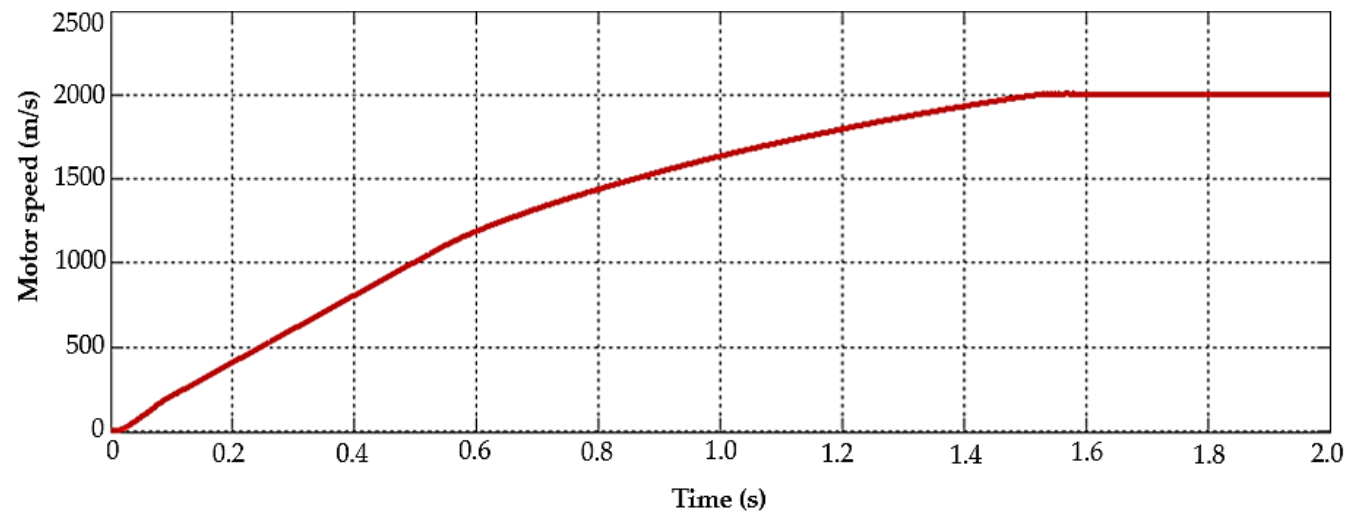

Figure 10. Steady-state response of the BLDC motor speed.

Figure 11 shows the torque waveform of the BLDC motor before using the LUO converter. Here, the starting torque is high and is equal to $6 \mathrm{Nm}$, and the steady-state torque occurs at $0.12 \mathrm{~s}$ with a ripple of $5.5 \mathrm{Nm}$. Figure 12 shows the torque characteristics of the BLDC motor after using the LUO converter, as a result of which the ripples are reduced.

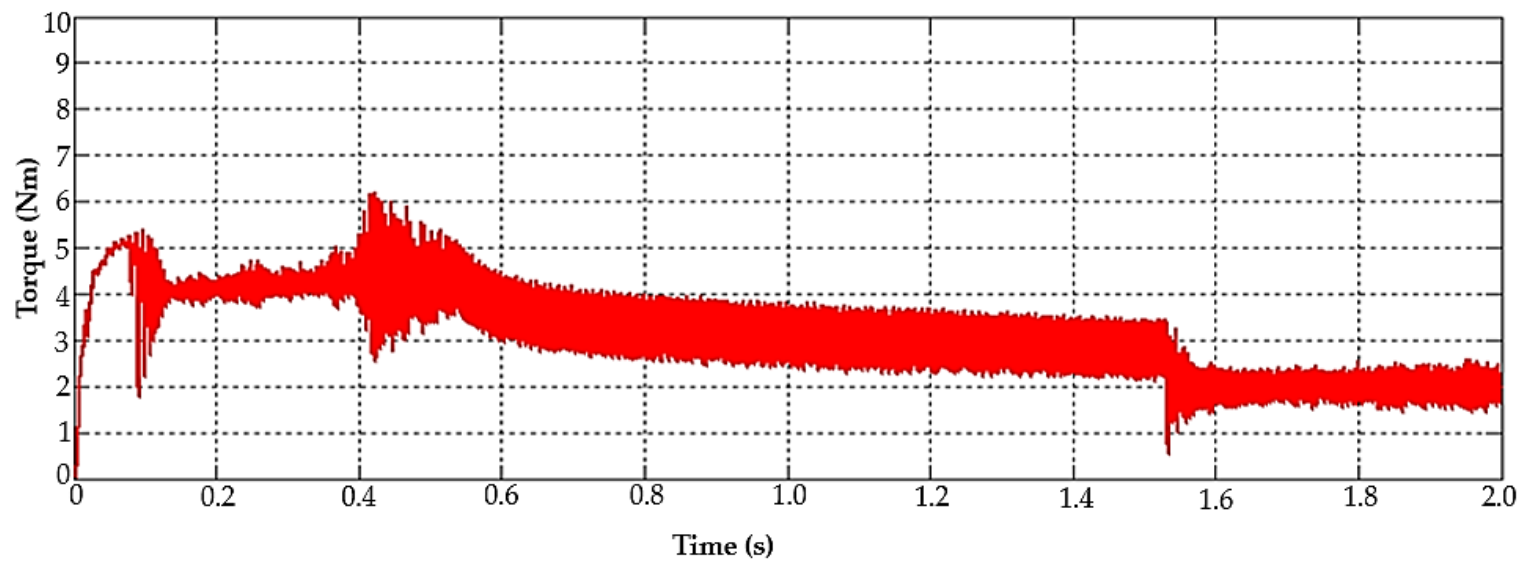

Figure 11. Output load torque characteristics of the BLDC motor before using the LUO converter.

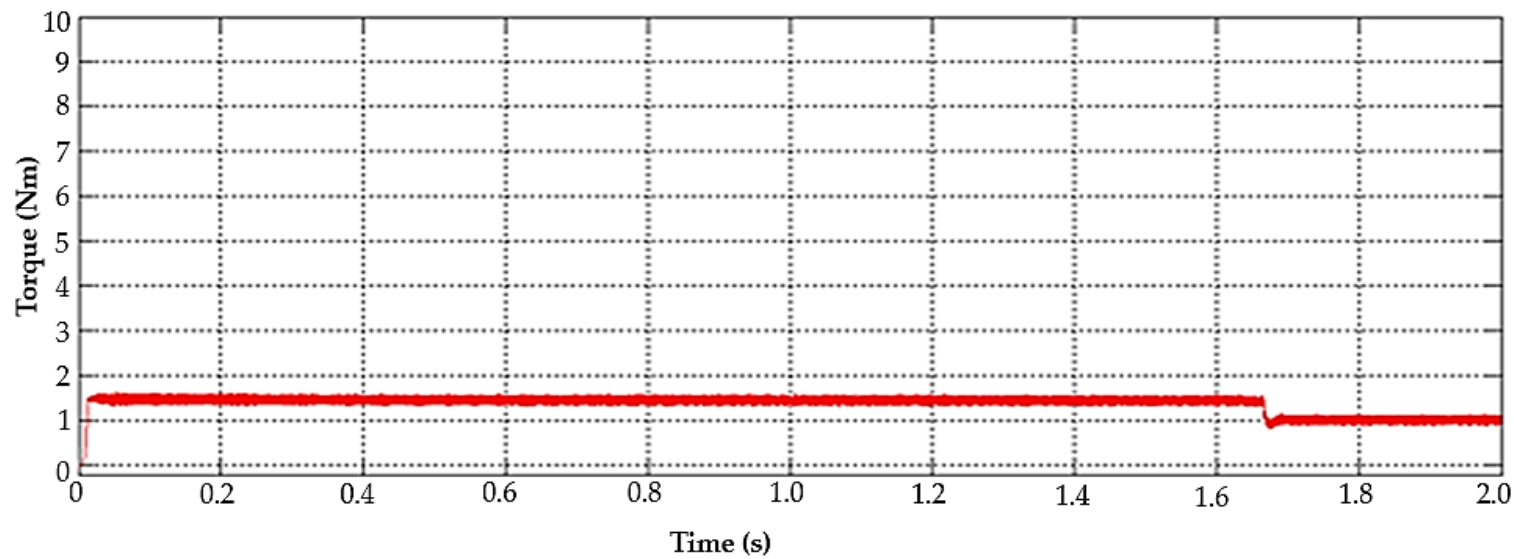

Figure 12. Output load torque characteristics of the BLDC motor after using the LUO converter. 
The comparative results are given in Table 2, where it is seen that the proposed system is more efficient when compared to other MPPT algorithms and converter topologies, with an efficiency of $97.8 \%$. The settling time and the output voltage gain are also better when compared to other methods. Usually, the optimization technique consumes significantly more time, which is, however, less than the manual tuning of the PI controller. Table 2 mentions the time taken by the system to settle after the tuning process is completed. The literature also shows that for a particular PI controller, it takes $10 \mathrm{~s}$, whereas it is reduced to $4 \mathrm{~s}$ when using an optimization technique.

Table 2. Comparison of the MPPT methods for the elementary and modified LUO converters with $\mathrm{V}_{\text {in }}=56 \mathrm{~V}$.

\begin{tabular}{ccccc}
\hline \multirow{2}{*}{ MPPT Methods /Converter. } & $\begin{array}{c}\text { Steady-State } \\
\text { Settling Time (s) }\end{array}$ & $\begin{array}{c}\text { Output Voltage } \\
\text { (V) }\end{array}$ & Efficiency (\%) \\
\hline \multirow{2}{*}{ P\&O } & Elementary LUO Converter & 0.02 & 280 & 86 \\
\cline { 2 - 5 } & Modified LUO Converter & 0.019 & 283 & 88 \\
\hline \multirow{2}{*}{ Fuzzy } & Elementary LUO Converter & 0.018 & 285 & 92 \\
\cline { 2 - 5 } & Modified LUO Converter & 0.016 & 289 & 94 \\
\hline \multirow{2}{*}{ GWO } & Elementary LUO Converter & 0.01 & 293 & 95.6 \\
\cline { 2 - 5 } & Modified LUO Converter & 0.009 & 298 & 97.8 \\
\hline
\end{tabular}

Figure 13 shows the output voltage comparison of different MPPT methods. As the progression reaches the proposed method, the performance (higher output voltage) of the developed method (modified LUO converter with GWO) shows more improvement than the existing approaches. Figure 14 shows the efficiency comparison of the different MPPT methods. As the progression reaches the proposed method, the performance (higher efficiency) of the developed method (modified LUO converter with GWO) shows more improvement than the existing approaches.

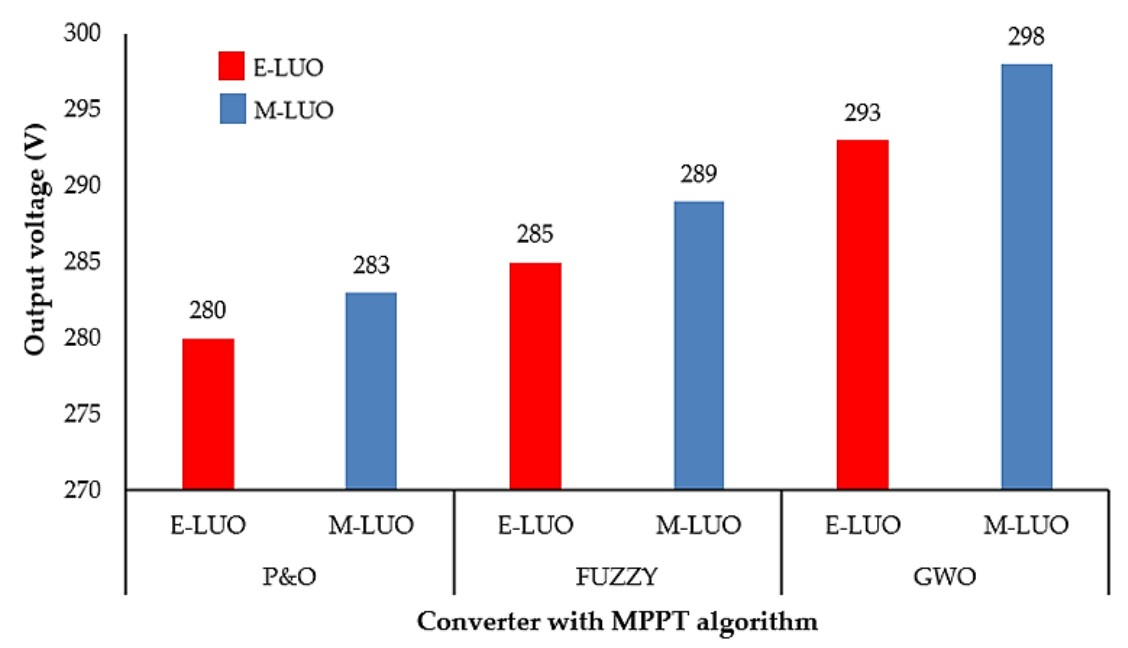

Figure 13. Output voltage comparison of different MPPT methods for the elementary and modified LUO converters (E-LUO and M-LUO). 


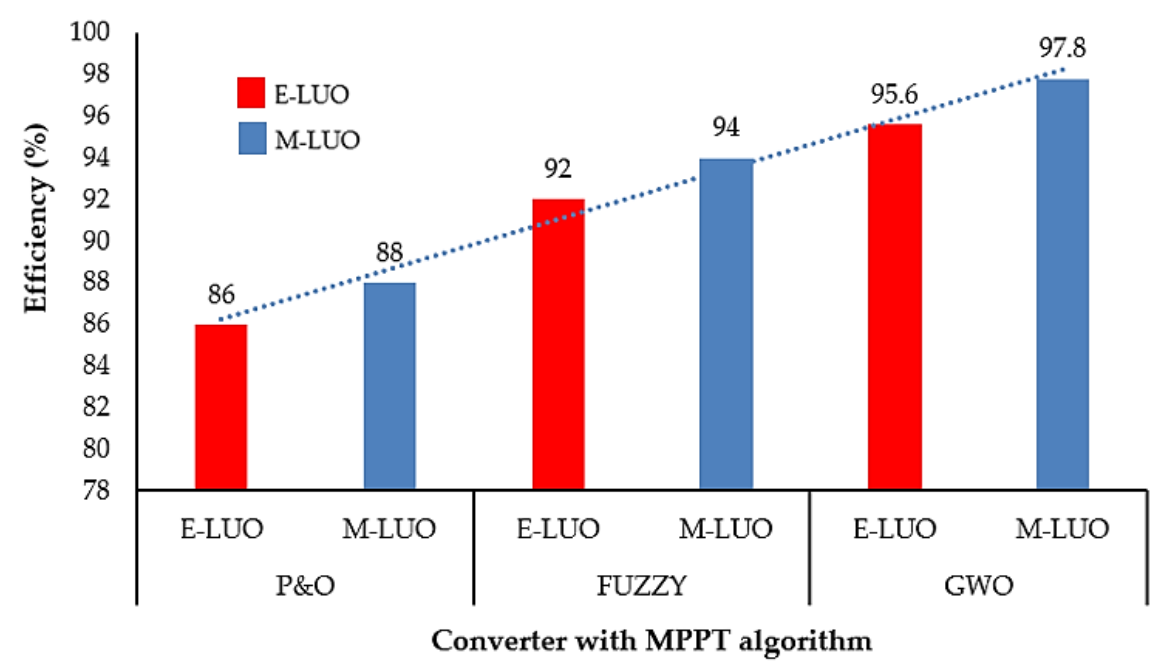

Figure 14. Efficiency comparison of the different MPPT methods for the elementary and modified LUO converters (E-LUO and M-LUO).

\subsection{Experimental Results}

The proposed method was verified experimentally by conducting a real-time test study. A practical setup was developed: first, the LUO converter and controller circuit designs were developed as demanded by the simulation requirements. The experimental setup shown in Figure 15 includes this designed controller and converter, along with the few additional components like the voltage source inverter, autotransformer, rheostat and BLDC motor. In Figure 16a, the output voltage of the PV panel is shown. This voltage consists of higher-order ripple contents which are oscillatory. For reduce this problem, the voltage is fed to the modified LUO converter. Figure $16 \mathrm{~b}$ shows the modified LUO converter output voltage. This constant and ripple-free voltage is achieved using the LUO converter and its optimized MPPT algorithm. This constant voltage is fed to the three-phase inverter which converts the DC voltage into AC voltage.

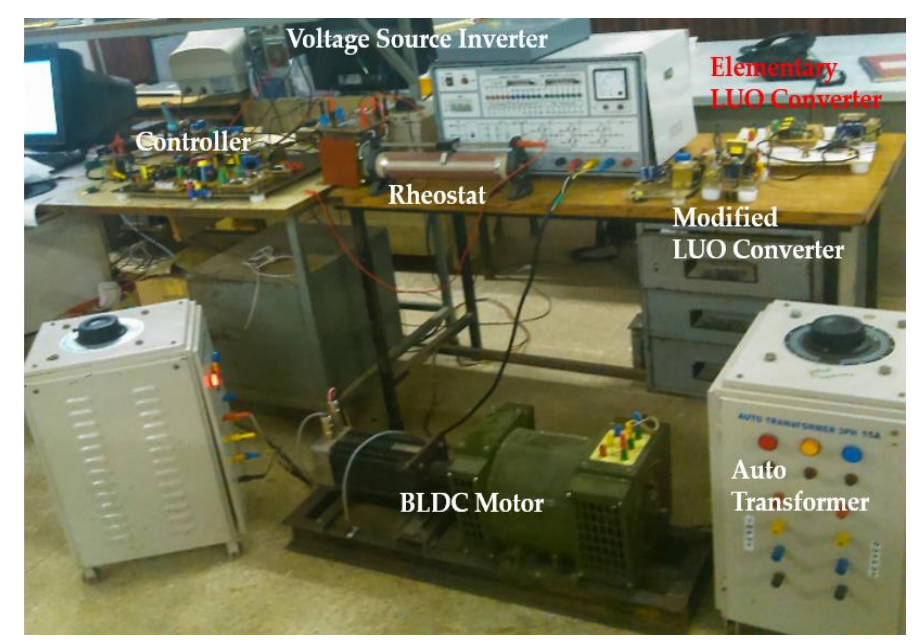

Figure 15. Experimental setup of the proposed system. 
a)

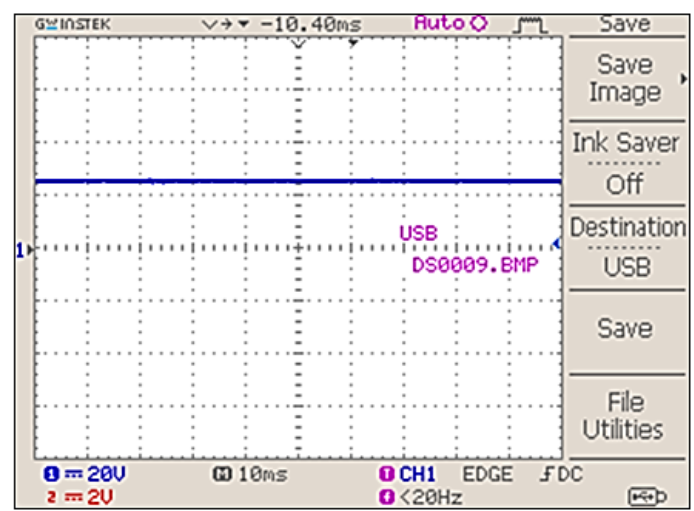

b)

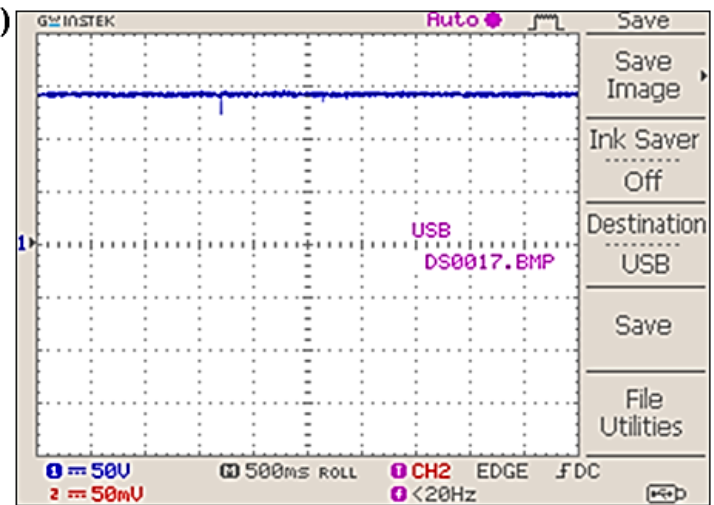

Figure 16. (a) Solar panel output voltage waveform; (b) Modified LUO converter output voltage waveform.

Figure 17 shows the PWM pulses fed to the switching devices of the voltage source inverter. The PI controller manages the pulse width for speed compensation. The dsPIC produces PWM pulses with a switching frequency of $10 \mathrm{kHz}$.

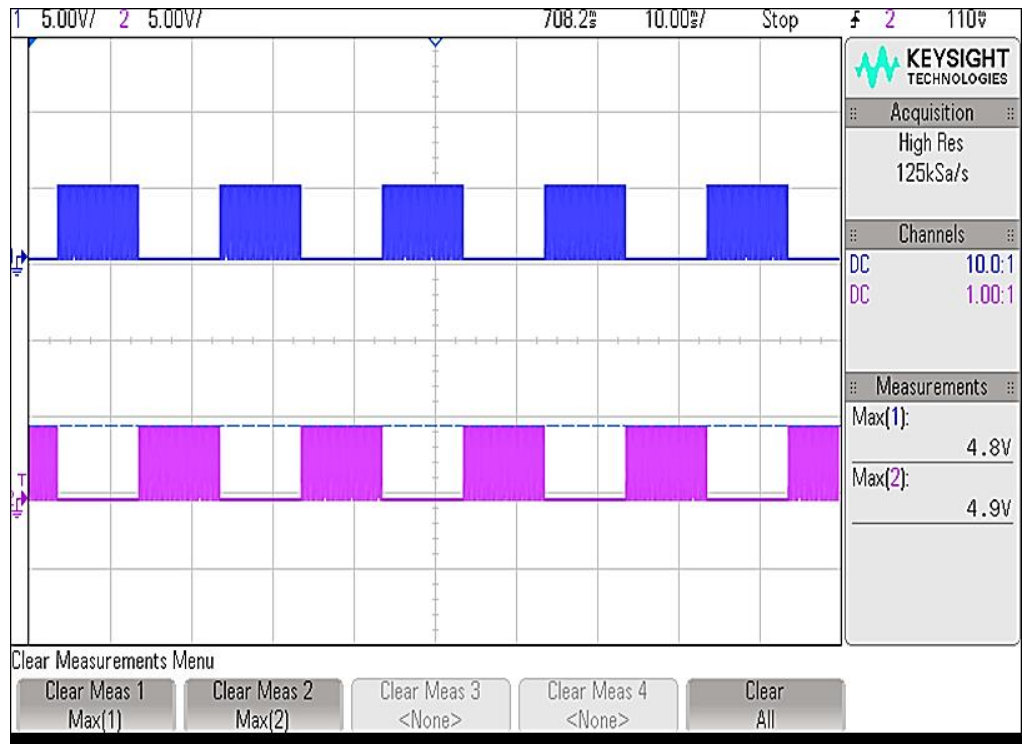

Figure 17. Voltage source inverter Pulse Width Modulation (PWM) pulses.

Figure 18 shows the position of the rotor signal from the three hall effect sensors which are mounted on the stator. Based on the rotor position signals, the electronic commutator switches are energised. Figure 19 shows the output voltage from the three-phase voltage source inverter, which also includes back emf. Due to the presence of this back emf, the supply voltage is trapezoidal.

Figure 20 shows the BLDC motor output current waveform. The modified LUO converter maintains the current within a specific limit. Figure 21 illustrates the speed waveform of the BLDC motor using the closed-loop PI control technique. Here, the reference speed and actual speed are compared and shown in the graph. The PI controller makes the speed constant in terms of the load. 


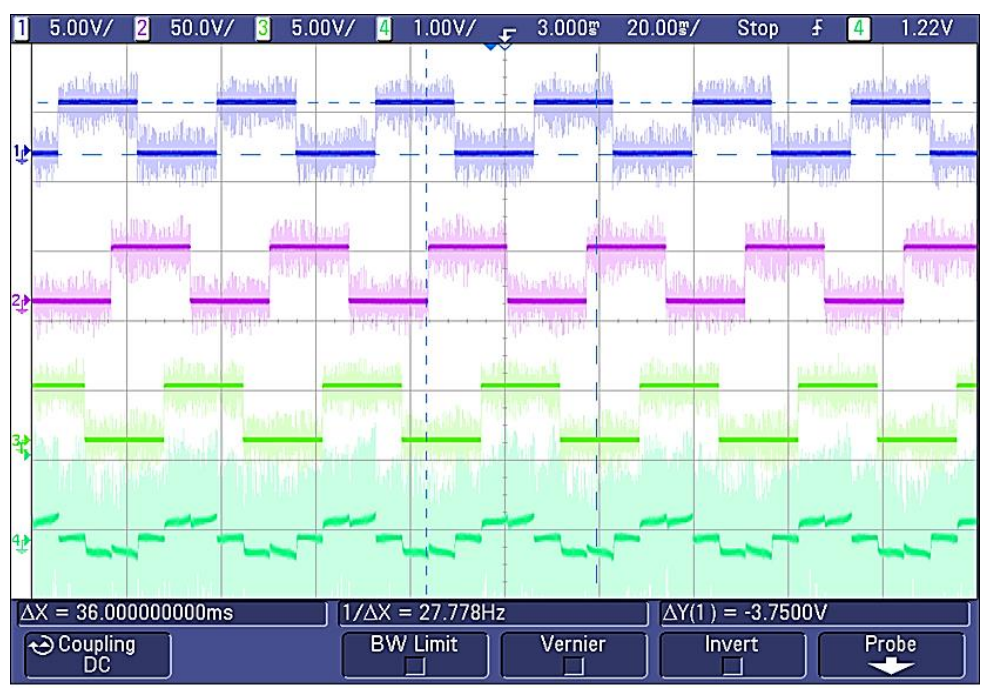

Figure 18. Hall sensor signals and stator current waveform of the BLDC motor.

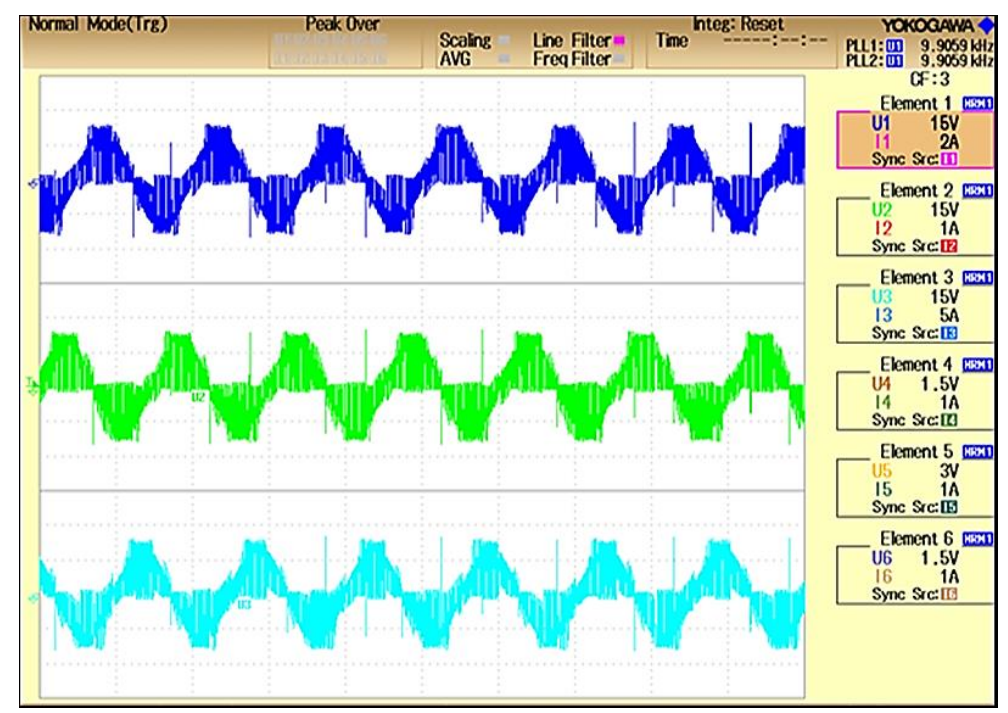

Figure 19. The output voltage waveform of the three-phase inverter.

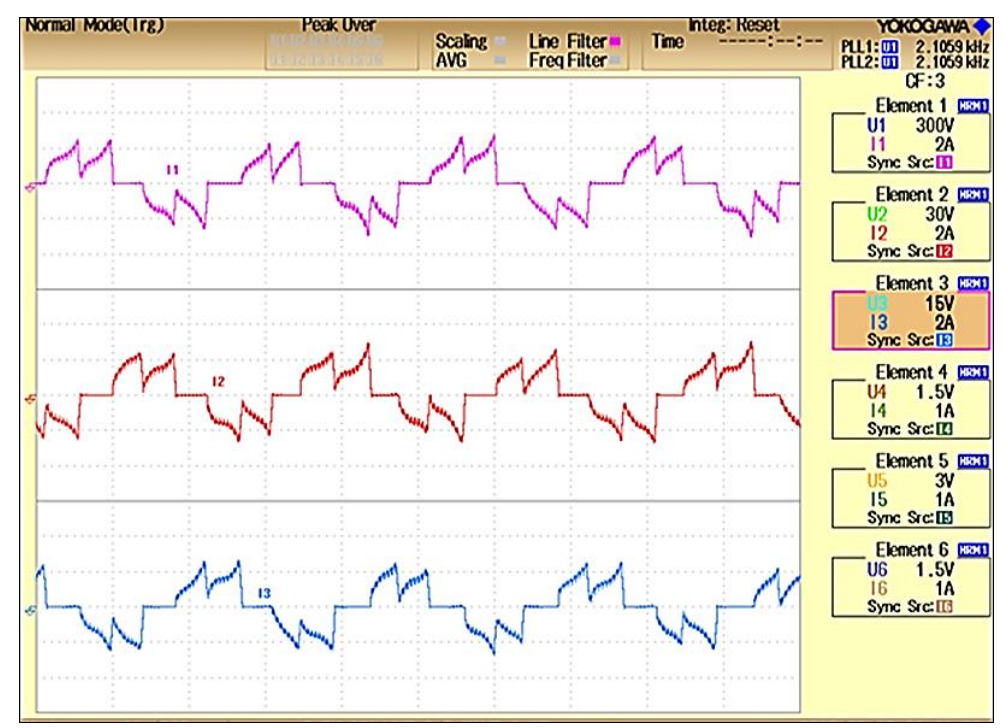

Figure 20. Voltage source inverter-fed BLDC motor output current waveform. 


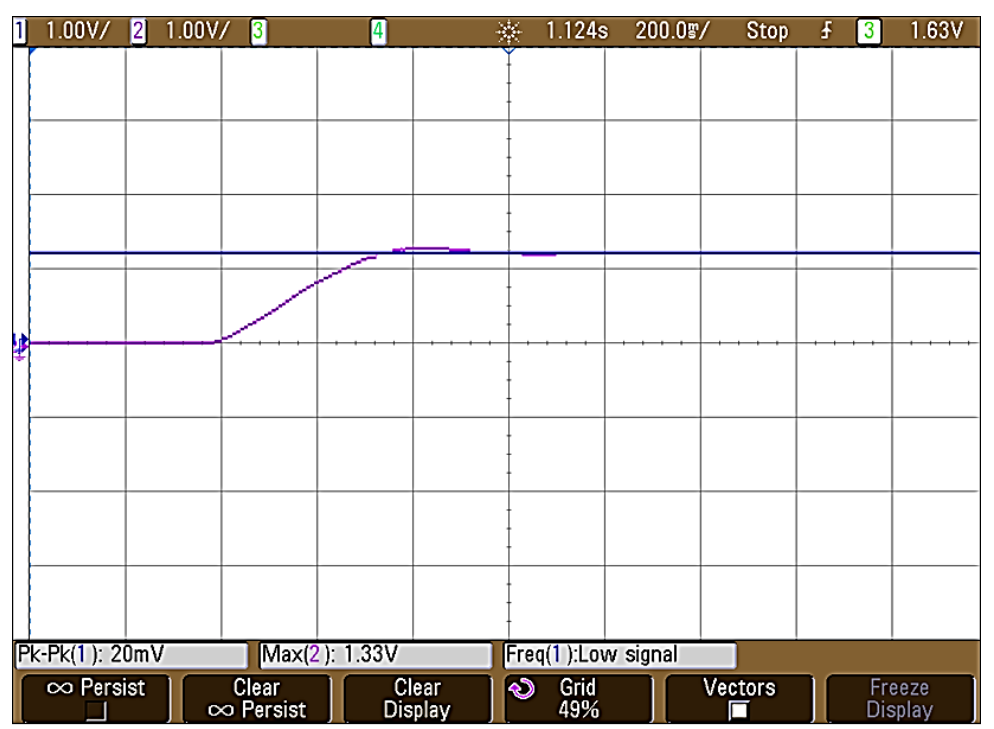

Figure 21. Speed waveform of the BLDC motor.

\section{Conclusions}

The modified LUO converter-fed VSI-BLDC motor with a solar PV array for a water pumping application was developed using MATLAB/Simulink and the Sim-power system toolbox, whose suitability was exhibited by simulated results. Initially, to meet the various desired objectives, the developed system was logically designed.

The proposed method was simulated and modelled to evaluate the performance under initial and steady-state conditions. The integration of the modified LUO converter was justified by evaluating its performance with the SPV array-based water pumping BLDC motor drive. The developed method availed many desired operations such as the absorption of MPP from the SPV array, BLDC motor soft starting, the fundamental switching frequency of the VSI (resulting in low switching losses), a reduction in the switch stress and the continuous conduction mode of the modified LUO converter for stable operation. Even at a very low solar irradiance, the developed method was operated successfully.

The GWO-optimized algorithm optimally extracted maximum power from the PV system when compared to the P\&O and Fuzzy logic MPPT algorithms. The scaling-up of the power rating of the motor and converter did not affect the performance of the pumping system unless the incoming torque of the motor was not affected by the converter. Hence, the proper design of the converter ensured the overall performance of the system. The system may be economical if it is operating with better performance; as stated earlier, the incoming torque has a direct effect on the performance, which affects the overall economic value. While scaling up the system, considering the performance based on the systems' service life is essential, and this will allow us to make decisions on when to change the converter if any operating issues occur. The regular maintenance of the converters may ensure economic gains from the system.

Furthermore, from the results, it was seen that the proposed system was more efficient when compared to other MPPT algorithms and converter topologies, with a maximum efficiency of $97.8 \%$. In comparison, the average performance shown by the Fuzzy optimized modified Luo converter was $94 \%$, and the lowest performance, about $86 \%$, as shown by the conventional $\mathrm{P} \& \mathrm{O}$ algorithm. The settling time was also better when compared to other methods, with a minimum settling time of $0.009 \mathrm{~s}$ for GWO and of $0.02 \mathrm{~s}$ for the P\&O algorithm. Similarly, the voltage gain of the proposed method was higher, with a voltage of $298 \mathrm{~V}$, while for Fuzzy and P\&O it was $289 \mathrm{~V}$ and $280 \mathrm{~V}$. The experimental outcomes were validated with the simulated results.

Furthermore, this work plans to extend the performance analysis of the BLDC pumping motor for a higher-rated three-phase power system with the proposed converter. 
Author Contributions: Data curation, A.D.G.J., and M.S.P.S.; Formal analysis, A.D.G.J., M.S.P.S., and N.M.K.; Funding acquisition, U.S., and S.P.; Methodology, A.D.G.J., and M.S.P.S.; Resources, M.S.P.S., and N.M.K.; Software, A.D.G.J.; Supervision, M.S.P.S.; Visualization, N.M.K., and S.P.; Writing-original draft, A.D.G.J.; Writing-review \& editing, M.S.P.S., N.M.K., U.S., and S.P. All authors have read and agreed to the published version of the manuscript.

Funding: This research received no external funding.

Acknowledgments: The authors like to express their sincere gratitude to the Department of Energy Technology, Aalborg University, Esbjerg, Denmark, and Renewable Energy research lab, College of Engineering, Prince Sultan University, Riyadh, Saudi Arabia, for providing technical inputs.

Conflicts of Interest: The authors declare no conflict of interest.

\section{References}

1. Bist, V. An Adjustable Speed PFC Bridgeless-SEPIC. In Proceedings of the 2015 IEEE Energy Conversion Congress and Exposition (ECCE), Montreal, QC, Canada, 20-24 September 2015; pp. 4886-4893.

2. Hong, D.K.; Woo, B.C.; Koo, D.H.; Seo, U.J. A single-phase brushless DC motor with improved high efficiency for water cooling pump systems. IEEE Trans. Magn. 2011, 47, 4250-4253. [CrossRef]

3. Chand, V.; Kalamkar, V.R. Solar photovoltaic water pumping system-A comprehensive review. Renew. Sustain. Energy Rev. 2016, 59, 1038-1067.

4. Singh, S.; Singh, B. Power factor correction in permanent magnet brushless DC motor drive using single-phase Cuk converter. J. Eng. Sci. Technol. 2010, 5, 412-425.

5. Shi, T.; Guo, Y.; Song, P.; Xia, C. A New Approach of Minimizing Commutation Torque Ripple for Brushless DC Motor Based on DC-DC Converter. IEEE Trans. Ind. Electron. 2010, 57, 3483-3490. [CrossRef]

6. Hendershot, J.R.; Miller, T.J.E. Design of Brushless PM Motors; Magna Publishing: Hillsborough, $\mathrm{OH}$, USA, 1994.

7. Mandel, Y.; Weiss, G. Reduction of torque ripple in brushless DC motor drives. IFAC Proc. Vol. 2009, 42, 84-89. [CrossRef]

8. Bahari, N.B.; Jidin, A.B.; Abdullah, A.R.B.; Othman, M.N.B.; Manap, M.B. Modeling and simulation of torque hysteresis controller for brushless DC motor drives. In Proceedings of the 2012 IEEE Symposium on Industrial Electronics and Applications, Bandung, Indonesia, 23-26 September 2012; pp. 152-155.

9. Mohanty, S.; Subudhi, B.; Member, S.; Ray, P.K. A New MPPT Design Using Grey Wolf Optimization Technique for Photovoltaic System Under Partial Shading Conditions. IEEE Trans. Sustain. Energy 2015, 7, 1-8. [CrossRef]

10. G, D.; Singh, S.N. Selection of non-isolated DC-DC converters for solar photovoltaic system. Renew. Sustain. Energy Rev. 2017, 76, 1230-1247. [CrossRef]

11. Singh, B.; Singh, S.; Chandra, A.; Al-Haddad, K. Comprehensive study of single-phase AC-DC power factor corrected converters with high-frequency isolation. IEEE Trans. Ind. Inform. 2011, 7, 540-556. [CrossRef]

12. Zhang, X.; Lu, Z. A new BLDC motor drives method based on BUCK converter for torque ripple reduction. In Proceedings of the 2006 CES/IEEE 5th International Power Electronics and Motion Control Conference, Shanghai, China, 14-16 August 2006; Volume 3, pp. 1631-1635.

13. Richter, M. Zeitverschwendung. Dtsch. Arztebl. Int. 2017, 114, A2358.

14. Singh, B.; Bist, V. A BL-CSC converter-fed BLDC motor drive with power factor correction. IEEE Trans. Ind. Electron. 2015, 62, 172-183. [CrossRef]

15. Singh, P.K.; Singh, B.; Bist, V. PFC converter based power quality improvement and ripple current minimization in BLDC motor drive. In Proceedings of the 2016 IEEE 6th International Conference on Power Systems (ICPS), New Delhi, India, 4-6 March 2016; pp. 1-6.

16. Bist, V.; Singh, B. PFC Cuk converter-fed BLDC motor drive. IEEE Trans. Power Electron. 2015, 30, 871-887. [CrossRef]

17. Kumar, R.; Singh, B. Buck-Boost Converter Fed BLDC Motor Drive for Solar PV Array Based Water Pumping. In Proceedings of the 2014 IEEE International Conference on Power Electronics, Drives and Energy Systems (PEDES), Mumbai, India, 16-19 December 2014; p. 4.

18. Kumar, R.; Singh, B. BLDC Motor-Driven Solar PV Array-Fed Water Pumping System Employing Zeta Converter. IEEE Trans. Ind. Appl. 2016, 52, 2315-2322. [CrossRef] 
19. Berkovich, Y.; Madar, R.; Axelrod, B.; Twina, A. Improved Luo converter modifications with increasing voltage ratio. IET Power Electron. 2015, 8, 202-212. [CrossRef]

20. Kumar, R.; Singh, B. Solar PV array fed cuk converter-VSI controlled BLDC motor drive for water pumping. In Proceedings of the 2014 6th IEEE Power India International Conference (PIICON), Delhi, India, 5-7 December 2014; pp. 1-31.

21. Sivakumar, S.; Sathik, M.J.; Manoj, P.S.; Sundararajan, G. An assessment on performance of DC-DC converters for renewable energy applications. Renew. Sustain. Energy Rev. 2016, 58, 1475-1485. [CrossRef]

22. Oshaba, A.S.; Ali, E.S.; Elazim, S.M.A. MPPT Control Design of PV Generator Powered DC Motor-Pump System based on Artificial Bee Colony Algorithm. WSEAS Trans. POWER Syst. 2016, 11, 190-198.

23. El-samahy, A.A.; Shamseldin, M.A. Brushless DC motor tracking control using self-tuning fuzzy PID control and model reference adaptive control. Ain Shams Eng. J. 2018, 9, 341-352. [CrossRef]

24. Premkumar, K.; Manikandan, B.V. Engineering Science and Technology, an International Journal Bat algorithm optimized fuzzy PD based speed controller for brushless direct current motor. Eng. Sci. Technol. Int. J. 2016, 19, 818-840.

25. Depuru, S.R.; Mahankali, M. Boost converter Fed High Performance BLDC Drive for Solar PV array Powered Air Cooling System. Power Eng. Electr. Eng. 2017, 15, 154-168. [CrossRef]

26. Akkaya, R.; Kulaksiz, A.A.; Aydoğdu, Ö. DSP implementation of a PV system with GA-MLP-NN based MPPT controller supplying BLDC motor drive. Energy Convers. Manag. 2007, 48, 210-218. [CrossRef]

27. Femia, N.; Petrone, G.; Spagnuolo, G.; Vitelli, M. Optimization of perturb and observe maximum power point tracking method. IEEE Trans. Power Electron. 2005, 20, 963-973. [CrossRef]

28. Killi, M.; Samanta, S. Modified perturb and observe MPPT algorithm for drift avoidance in photovoltaic systems. IEEE Trans. Ind. Electron. 2015, 62, 5549-5559. [CrossRef]

29. Hohm, D.P.; Ropp, M.E. Comparative study of maximum power point tracking algorithms using an experimental, programmable, maximum power point tracking test bed. In Proceedings of the Conference Record of the Twenty-Eighth IEEE Photovoltaic Specialists Conference-2000, Anchorage, AK, USA, 15-22 September 2000; pp. 1699-1702.

30. Terki, A.; Moussi, A.; Betka, A.; Terki, N. An improved efficiency of fuzzy logic control of PMBLDC for PV pumping system. Appl. Math. Model. 2012, 36, 934-944. [CrossRef]

(C) 2020 by the authors. Licensee MDPI, Basel, Switzerland. This article is an open access article distributed under the terms and conditions of the Creative Commons Attribution (CC BY) license (http://creativecommons.org/licenses/by/4.0/). 